\title{
Chapter 9 \\ Problematising Video as Data in Three Video-based Research Projects in Mathematics Education
}

\author{
Man Ching Esther Chan, Carmel Mesiti and David Clarke
}

\begin{abstract}
In this chapter, we problematise the status of video as research data and identify ontological contingencies relevant to any research study by considering three video-based research projects in which the relationship between researcher and video material (i.e., between researcher and data) is very different. Each project (the Learner's Perspective Study, the Social Unit of Learning Project, and The International Classroom Lexicon Project) employs video material in a distinctive way, and comparison of the three studies illustrates important ontological decisions that should be addressed explicitly in educational research projects.
\end{abstract}

Keywords Video-based research · Ontology $\cdot$ Metaphors · Research design

\subsection{Introduction}

The increasing variety of theories and analytical perspectives employed to investigate educational settings, situations and issues over recent decades has created challenges for researchers to communicate their research, integrate empirical results, and make progress as a field by building upon the growing diversity of empirical research (Prediger et al. 2008). In particular, what constitute valid research findings and research evidence is of significance not only to researchers, but also to practitioners, policymakers, and other stakeholders (Schirmer et al. 2016; Simpson 2017). A major consideration regarding the validity of research

\footnotetext{
M. C. E. Chan $(\bowtie) \cdot$ C. Mesiti · D. Clarke

Melbourne Graduate School of Education, The University of Melbourne,

Melbourne, VIC, Australia

e-mail: mc.chan@unimelb.edu.au

C. Mesiti

e-mail: cmesiti@unimelb.edu.au

D. Clarke

e-mail: d.clarke@unimelb.edu.au

(C) The Author(s) 2019 
findings and research evidence in education research is the issue of ontology, which is "an area of philosophy that deals with the nature of being, or what exists" (Neuman 2014, p. 94). We argue that research in education needs to pay attention to the claims that are being made about the authority of research findings and the nature of the data from which those findings have been derived. These questions are fundamentally ontological questions because they concern whether or not our research findings are drawn from and relate to phenomena that are in any sense 'real'.

As a source of research data, video occupies an unusual and possibly a unique place in mediating between the conception of actual classroom practice and our ability to theorise about the characteristics of that practice. This is because the video is a very graphic representation of that practice and should be subject to careful ontological examination before claims are made about the authority invoked for any research-based recommendations regarding those classroom practices. In this chapter, we focus on video-based research that attempts to inform the actual practice of teachers. The word actual invokes the notion of ontology by positing the existence of a world where things happen, a world where there are things to be studied, and a world where practices could be informed by the results of that study. This posited relationship between video-based research and the settings and situations it seeks to both study and to inform represents an ontological position implicit in most video-based research studies.

In this chapter we take three research projects as illustrative cases, each employing video. Each project had a different research design, and we examine the role of the researcher and the status of the video records in each of these projects, specifically from an ontological perspective. We have purposefully chosen these three projects because the role that video plays and the role of the researcher in each are very different. As a result, the uses made of the video material in the different research studies are distinct, where the relationship between the video material and the researcher is fundamentally different in each study. Our view is that exploring this relationship between the researcher and the video material offers insights into important ontological considerations that apply to any study involving the use of video and, we would suggest, to any study of any type, because it foregrounds fundamental issues related to the nature of data and evidence in any study and the sorts of conclusions that can be drawn. The following sections provide some background about video-based research in education and a brief overview of the three projects: (i) The Learner's Perspective Study (an international comparative study of well-taught mathematics classes in over a dozen countries); (ii) The Social Unit of Learning project (an experimental study of social interaction during collaborative problem solving in mathematics); and (iii) The International Classroom Lexicon Project (an investigation of the pedagogical vocabulary of mathematics teachers in ten countries). 


\subsection{Video-Based Research in Education}

Video has become a popular contemporary research tool, providing a record of classroom activity rich in detail and sufficiently permanent to provide opportunities for re-analysis. In the past 50 years, learning in classroom settings became increasingly the subject of research and this interest was accompanied by the development of onsite real-time observational techniques (e.g., Amidon and Hough 1967; Beeby et al. 1979). Process-product research designs (e.g., Bourke 1984; Good and Grouws 1977) sought to identify statistically significant associations between classroom process variables (e.g., number of teacher questions) and product variables (typically measures of student achievement or attitude). Naturalistic case studies of student learning in authentic classroom settings (e.g., Clarke 2001; Cobb and Bauersfeld 1995; Erlwanger 1975) drew upon the practices of ethnographic research to understand the relationships between individuals, their practice, and their consequent learning in classroom settings.

Early attempts at on-site recording of classroom practice required the physical presence of researchers to use checklists or write field notes during their classroom observation. Both checklists and the field notes maintained by researchers involve high levels of researcher interpretation and limited opportunity for re-visiting the classroom situation being studied. This restricts the reliability of the research data and the validity of the inferences made based on such data. It was hoped that video would provide a less intrusive and more efficient means of generating detailed documentation of classroom practice, while allowing cross-validation and re-examination of the data (Hiebert et al. 2003). The affordability of video technologies and computer processing power has given rise to the increased use of video in classroom research. International comparative studies of classroom practice have been undertaken using video as a key data collection tool (e.g., Clarke et al. 2006b; Stigler and Hiebert 1999). More recently, university-based and school-based classrooms equipped with video and audio facilities have been set up around the world, such as in the USA, the Netherlands, and China (Chan et al. 2017). The three research projects chosen as illustrative cases in this chapter each employed video material in a distinctive way with a different research design.

\subsection{Three Research Projects in Mathematics Education Employing Video}

\subsubsection{The Learner's Perspective Study (LPS)}

The Learner's Perspective Study (Clarke et al. 2006b) was designed to examine the practices of eighth grade mathematics classrooms in a more integrated and comprehensive fashion than had been attempted in previous international studies. The project was originally designed to complement research studies reporting national 
norms of student achievement and teaching practices with an in-depth analysis of mathematics classrooms in Australia, Germany, Japan and the USA by foregrounding the learner's perspective on the practices of those classrooms. However, from its inception, research teams from other countries continued to join the LPS. The LPS project grew to accommodate 15 research teams situated in universities in Australia, China, the Czech Republic, Germany, Israel, Japan, Korea, New Zealand, Norway, the Philippines, Portugal, Singapore, South Africa, Sweden and the USA. This combination of countries gave good representation to different European and Asian educational traditions, affluent and less affluent school systems, and mono-cultural and multi-cultural societies.

Data generation in the LPS used a three-camera approach (Teacher camera, Student camera, Whole Class camera; see Fig. 9.1) that included the onsite mixing of the Teacher and Student camera images into a picture-in-picture video record (see Fig. 9.2) that was then used in post-lesson interviews with teachers and with students to stimulate participant reconstructive accounts of classroom events. These data were generated for sequences of at least ten consecutive lessons occurring in well-taught eighth grade mathematics classrooms from around the world. One of the significant and distinguishing characteristics of this study in comparison with previous research was the documentation of a sequence of lessons taught by each teacher, as opposed to single lessons (cf. Stigler and Hiebert 1999). One of the major influences on a teacher's purposeful selection of instructional strategies includes the situation of the lesson within the enfolding topic. The LPS design allowed for this consideration to be taken into account in the analysis of classroom practice.

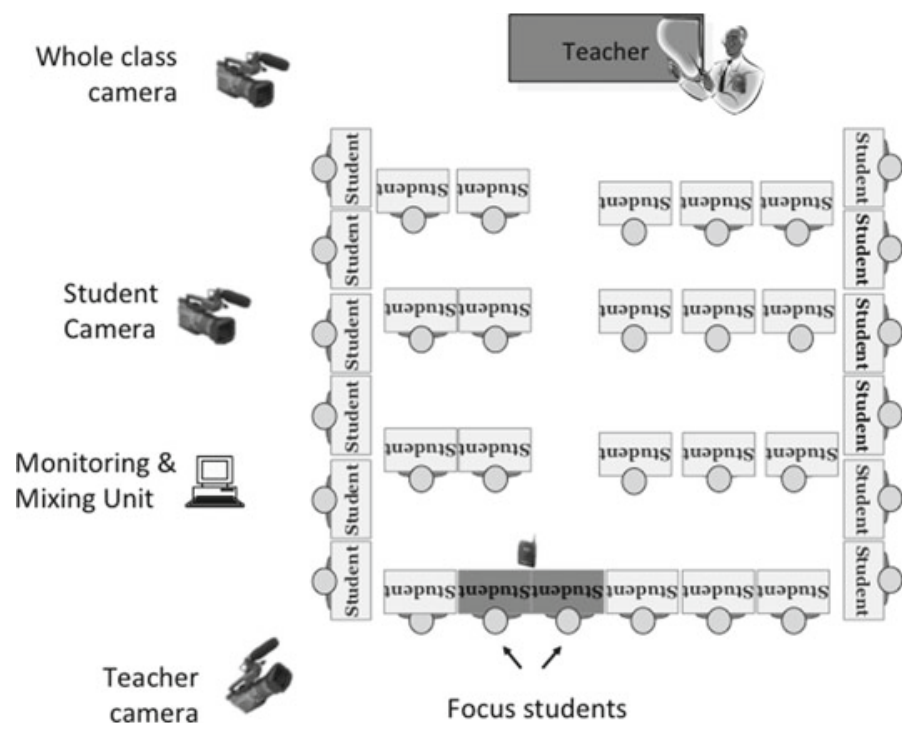

Fig. 9.1 Camera configuration in the LPS 
Fig. 9.2 Picture-in-picture video display. (Image reproduced from Clarke 2006, p. 21)

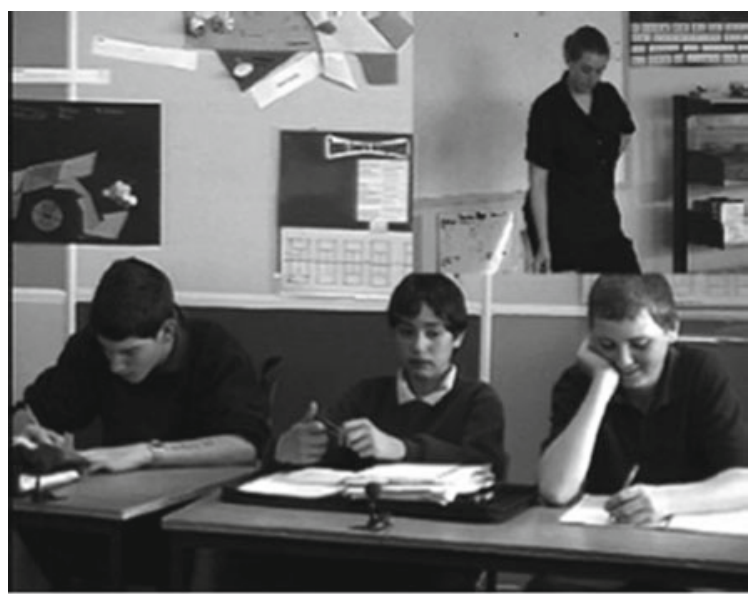

The use of three video-cameras in the classroom, supplemented by post-lesson video-stimulated interviews, provided a data base sufficiently complex to support analysis of both individual learners' constructed meanings and their perspectives on classroom practice, as well as documenting behavioural norms characteristic of each class. In particular, the LPS study facilitated the comparison of quality mathematics teaching practices across a wide variety of school systems situated in different countries, by identifying similarities and differences in both teaching practice and in the associated student perceptions and behaviours in each classroom.

One of the main findings of the LPS was contesting the characterisation of national patterns of teaching as stable, distinctive lesson structures, as reported by Stigler and Hiebert (1999). Stigler and Hiebert contended that mathematics teaching in Germany, Japan and the USA could be described by a "simple, common pattern" (p. 82) referred to as a culturally-based 'lesson script'. The lesson pattern for Japan was reported as: Reviewing the previous lesson; Presenting the problem for the day; Students working individually or in groups; and Discussing solution methods (p. 79).

The LPS (Clarke et al. 2006a) documented sequences of ten lessons in the classrooms of three competent Japanese mathematics teachers (in demographically different schools in Tokyo). Each of these lessons was analysed using the categories specified by Stigler and Hiebert (1999) (see Fig. 9.3). Figure 9.4 shows the distribution of these categories across the 30 Japanese lessons recorded in the LPS.

Not one lesson matched the 'typical' sequence reported by Stigler and Hiebert (Clarke et al. 2006c). With hindsight, this is not a surprising result. Any aggregated characterisation across a phenomenon as demonstrably variable as the mathematics lesson is almost certain to produce a 'stereotype' that does not match any single instance of the aggregated phenomenon. Nonetheless, the status of the individual categories themselves was significantly enhanced by their capacity to account for almost every instance of lesson time. This result was equally true for the 30 lessons recorded in the USA and in Germany. In each case, no instance of the reported 


\begin{tabular}{|c|c|}
\hline Reviewing the previous lesson \\
\hline Presenting the problem for the day \\
\hline Students working individually or in groups \\
\hline Discussing solution methods \\
\hline Highlighting and summarizing the major points \\
\hline
\end{tabular}

Fig. 9.3 Video coding key for the classroom activities found in the Japanese lessons. (Image reproduced from Clarke et al. 2006c, p. 38)
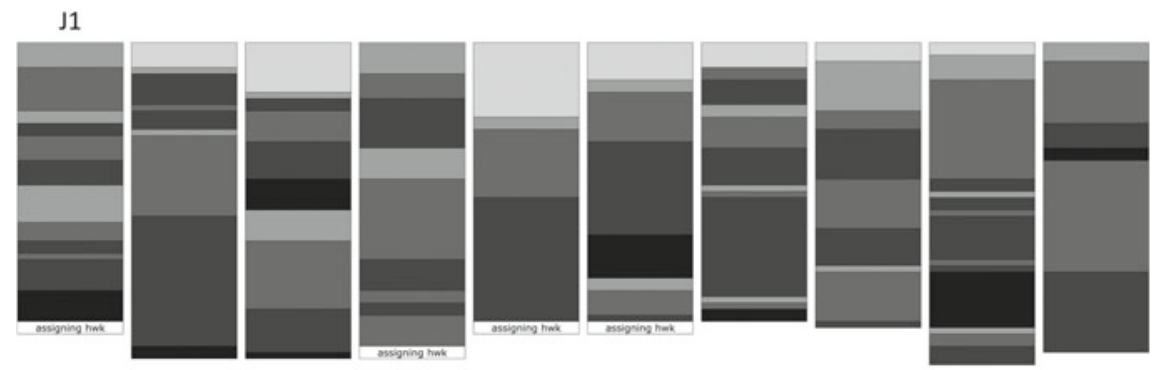

\section{$\mathrm{J} 2$}
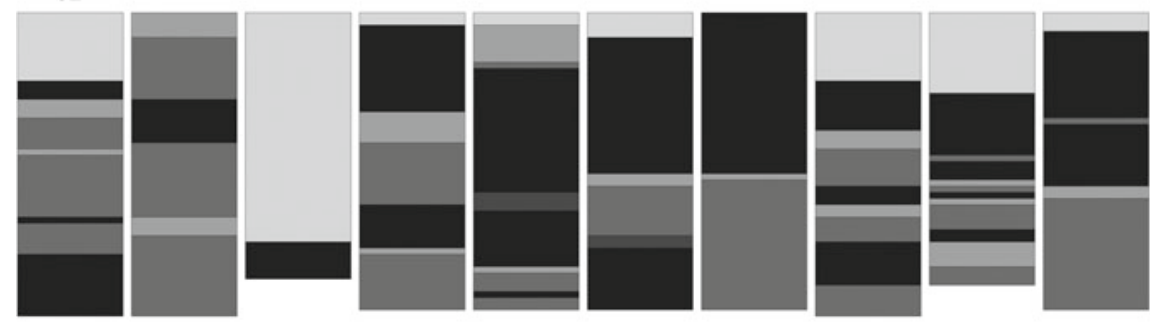

J3
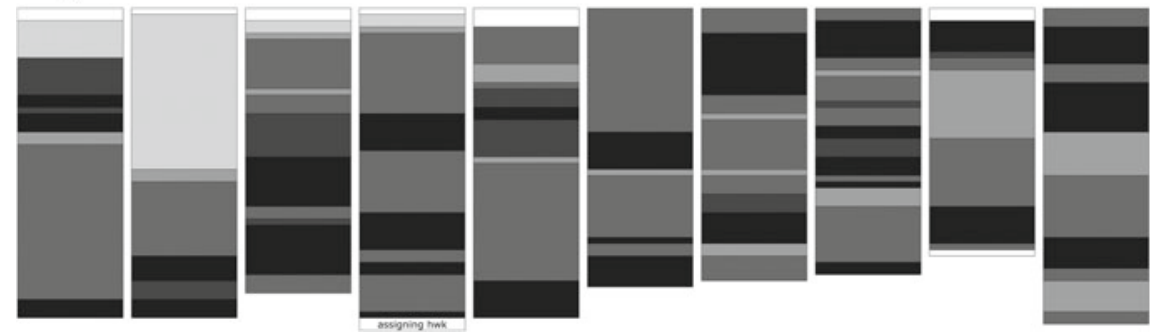

Fig. 9.4 Japanese lesson pattern codes as applied to LPS Japanese Schools 1, 2 and 3. (Images reproduced from Clarke et al. 2006c, pp. 38-39) 
lesson script could be found in the recorded lessons. However, the constituent elements of each lesson script were sufficiently robust to accommodate almost all classroom phenomena in each of the three countries (Japan, USA and Germany). The variability in lesson structure documented in the Learner's Perspective Study by Clarke, Mesiti, Jablonka and Shimizu reflects the purposeful decision-making of competent teachers, who structure their lessons in recognition of the needs of their students, their priorities and strengths as teachers, and the situation and consequent purpose of the lesson in the instructional sequence (cf. Givvin et al. 2005, p. 341).

\subsubsection{The Social Unit of Learning Project}

The Science of Learning Research Classroom (SLRC) at the University of Melbourne is a 129 sq. m. teaching space that resembles a typical school classroom, but is fitted with high definition audio-visual recording equipment and physically connected to an adjacent Control Room via a one-way window (see Fig. 9.5). The development of the SLRC laboratory classroom has made possible research designs that combine a good approximation to natural social settings with the retention of some degree of researcher control over the research setting, task characteristics, and possible forms of social interaction afforded or encouraged. Such designs allow conclusions to be drawn with greater confidence about connections between interactive patterns of social negotiation and associated knowledge products (learning). The SLRC had the capability to capture classroom social interactions with a rich amount of detail using advanced video technology. The facility was purposefully designed to allow simultaneous and continuous documentation of classroom interactions using multiple cameras and microphones.

The Social Unit of Learning Project (Chan et al. 2017) used the SLRC to examine individual, dyadic, small group (four to six students) and whole class problem solving in mathematics and the associated/consequent learning. The project aimed to investigate the social aspects of learning and, particularly, those aspects for which 'the social' represents the most fundamental and useful level of explanation, modelling and instructional intervention (Chan and Clarke 2017a). Figure 9.6 shows the classroom configuration for a filming session of the project.
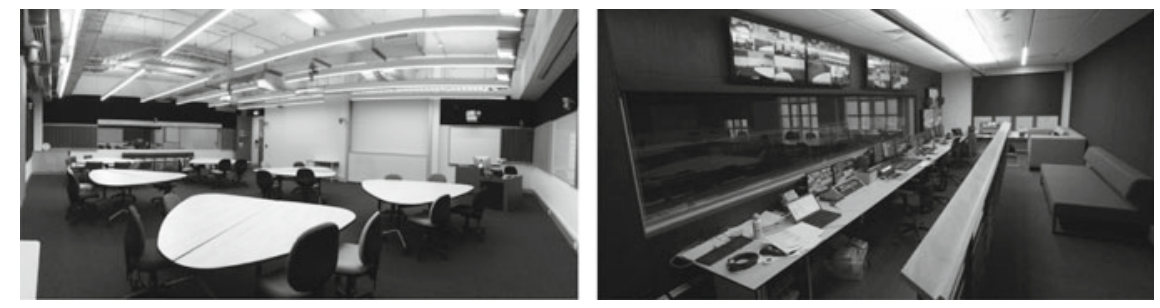

Fig. 9.5 Images of the science of learning research classroom (left) and the control room (right). (Images reproduced from Chan and Clarke 2019) 


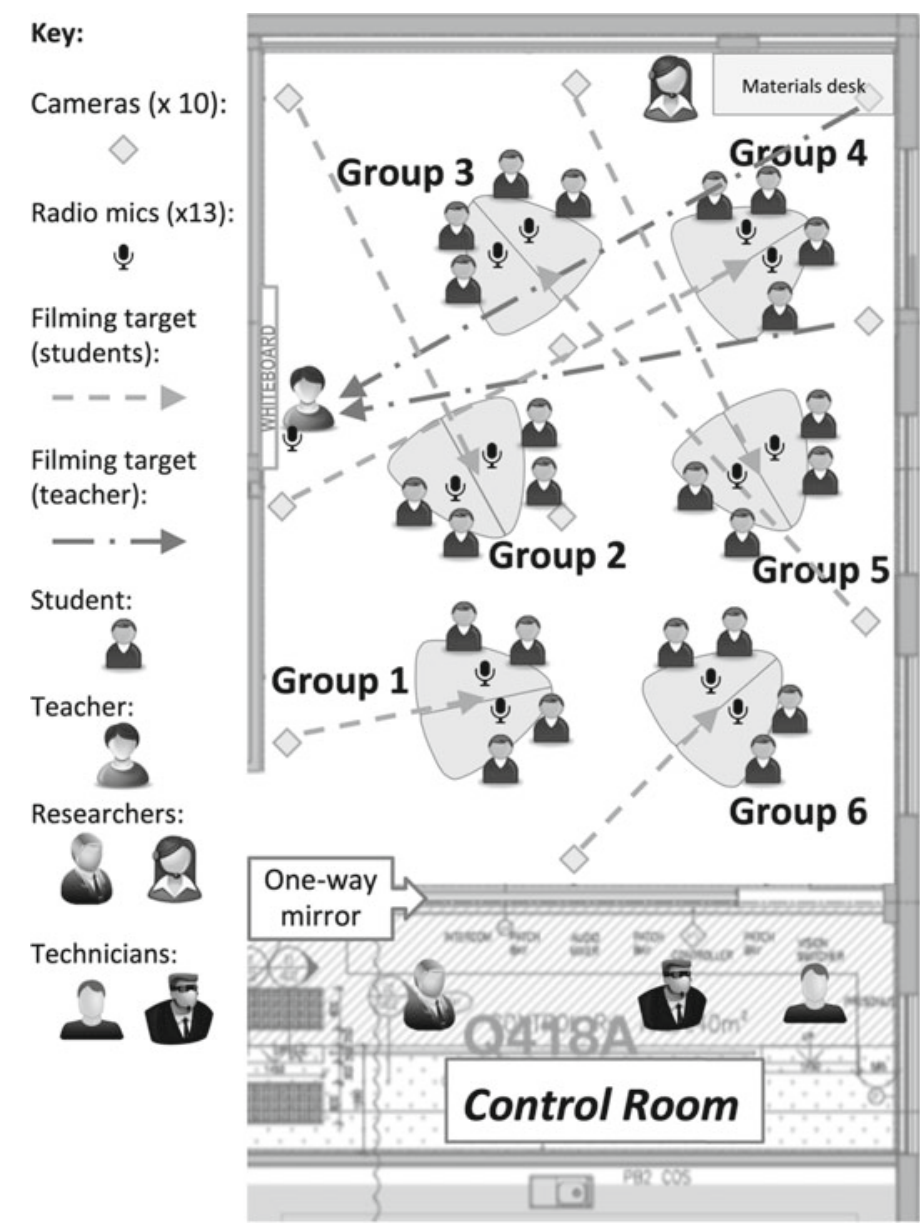

Fig. 9.6 Classroom configuration showing video camera sight lines. (Image reproduced from Chan et al. 2017, p. 46)

The Social Unit of Learning project collected multiple forms of data for analysis, including student written products and high definition video and audio recordings of every student and the teacher in the classroom. The project employed a multitheoretic research design (Clarke et al. 2012) which afforded the examination of the complex data set from multiple perspectives by multiple researchers, as well as the reciprocal interrogation of the different theoretical perspectives through answering research questions such as the following:

1. What commonalities and differences in process and product are evident during problem solving activities undertaken by learners as members of different social units (individual, pairs, small groups and whole class groupings)? 
2. Which existing theories best accommodate the documented similarities and differences in process and product and in what ways do the accounts generated by parallel analyses predicated on different theories lead to differences in instructional advocacy?

An international multi-disciplinary research team (combining education, cognitive and emotive psychology, learning analytics, and neuroscience perspectives) was recruited to develop analytical frames for coding the data, including analysis of the negotiative foci of student exchange (Chan and Clarke 2017b); sophistication in mathematical student-student exchange (Tran and Chan 2017); dialogic talk between students (Díez-Palomar 2017); student motivating desires (Tuohilampi 2018); and behavioural indicators of student engagement (Chan et al. in press), to name a few. The researchers each constructed distinct data sets according to different theoretical perspectives applied to the same set of video records and other supplementary data. The multitheoretic research design allowed the research team to juxtapose different interpretive accounts reflecting different theoretical positions in order to compare and contrast the capacity of different theories to characterise different aspects of the complex classroom setting; to examine their assumptions and implications, as well as their strengths and limitations.

\subsubsection{The International Classroom Lexicon Project (The Lexicon Project)}

The International Classroom Lexicon Project set out to document the professional language employed by teachers in ten countries (Australia, Chile, China, the Czech Republic, Finland, France, Germany, Japan, USA and Korea) to describe the phenomena typical of the middle school mathematics classroom. The researchers' interest in the Lexicon Project concerned the actual terms by which teachers in different countries named the objects and phenomena in their respective classrooms (Mesiti and Clarke 2017a). Documentation of the content and structure of classroom-related lexicons in ten countries revealed patterns of connection in the pedagogical terminology employed in each country. Each lexicon also articulated, in performative terms, cultural-historical differences in pedagogy, encrypted in the terms by which classroom phenomena are named and from which each community constructs its instructional practices and its theories of instruction and learning.

Each local research team contributed video material with time-stamped transcripts as well as supporting material related to one lesson of middle school mathematics. These lessons were re-packaged as "three-ups", that is, three camera angles (typically, whole class, teacher, and student videos) with a time-code and subtitles, all visible in one viewing window (see Fig. 9.7).

A stimulus package of lessons, one from each team, was constructed and distributed to each local project team (which included both researchers and experienced teachers) for project-wide use. These lessons presented a variety of classroom 


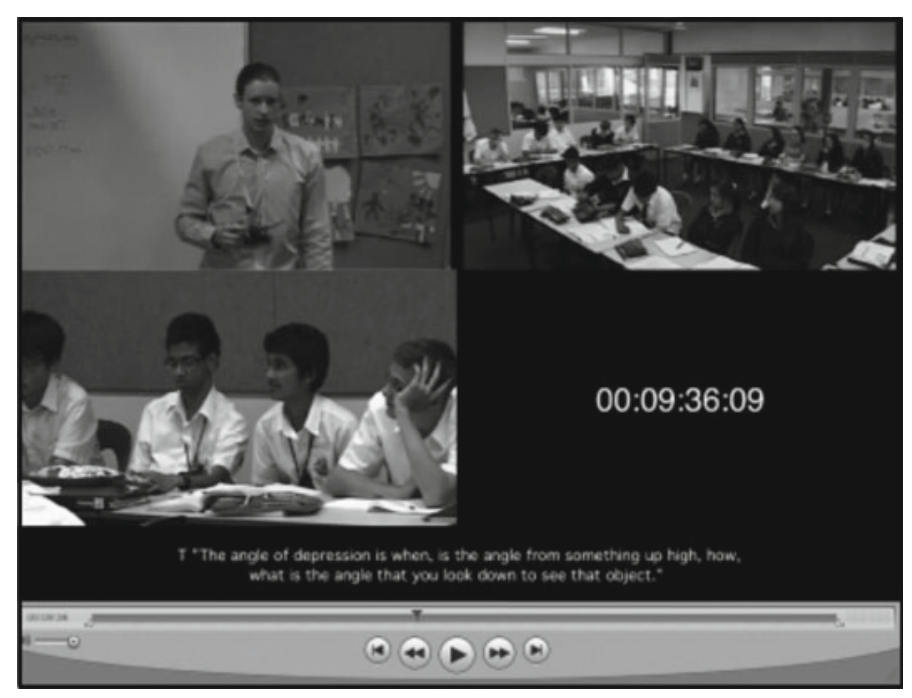

Fig. 9.7 The video "three-up": three camera angles with time-code and subtitles. (Image reproduced from Mesiti and Clarke 2017b, p. 375)

settings and instructional approaches, both familiar and unfamiliar to the research team members in any particular country.

Each team began their examination of the stimulus video material with the prompt "What do you see that you can name?" The classroom videos were intended to stimulate thinking about the possible terms of the lexicon. The essential point was to record single words or short phrases that were familiar, with an agreed meaning, to at least two-thirds of middle school mathematics teachers in each participating country. Operational descriptions were developed for each of the terms (see Fig. 9.8). National surveys were subsequently developed to collect information about teachers' level of familiarity with each of the terms, and the extent to which they endorsed the descriptions, examples and non-examples provided for each term in the lexicon. The goal was to establish that the constituent terms of the lexicon were not only familiar to the teaching community whose classroom phenomena were encoded in the lexicon, but also, that their meaning was represented in a way that teachers were happy to endorse.

\subsection{Ontological Grounding in Terms of Researcher Role and Status of the Video in Each Project}

When discussing the use of video in classroom research, Clarke and Chan (2019) highlighted that the decision to use video has important methodological and theoretical entailments. Characterising research as a constructive and interpretive 


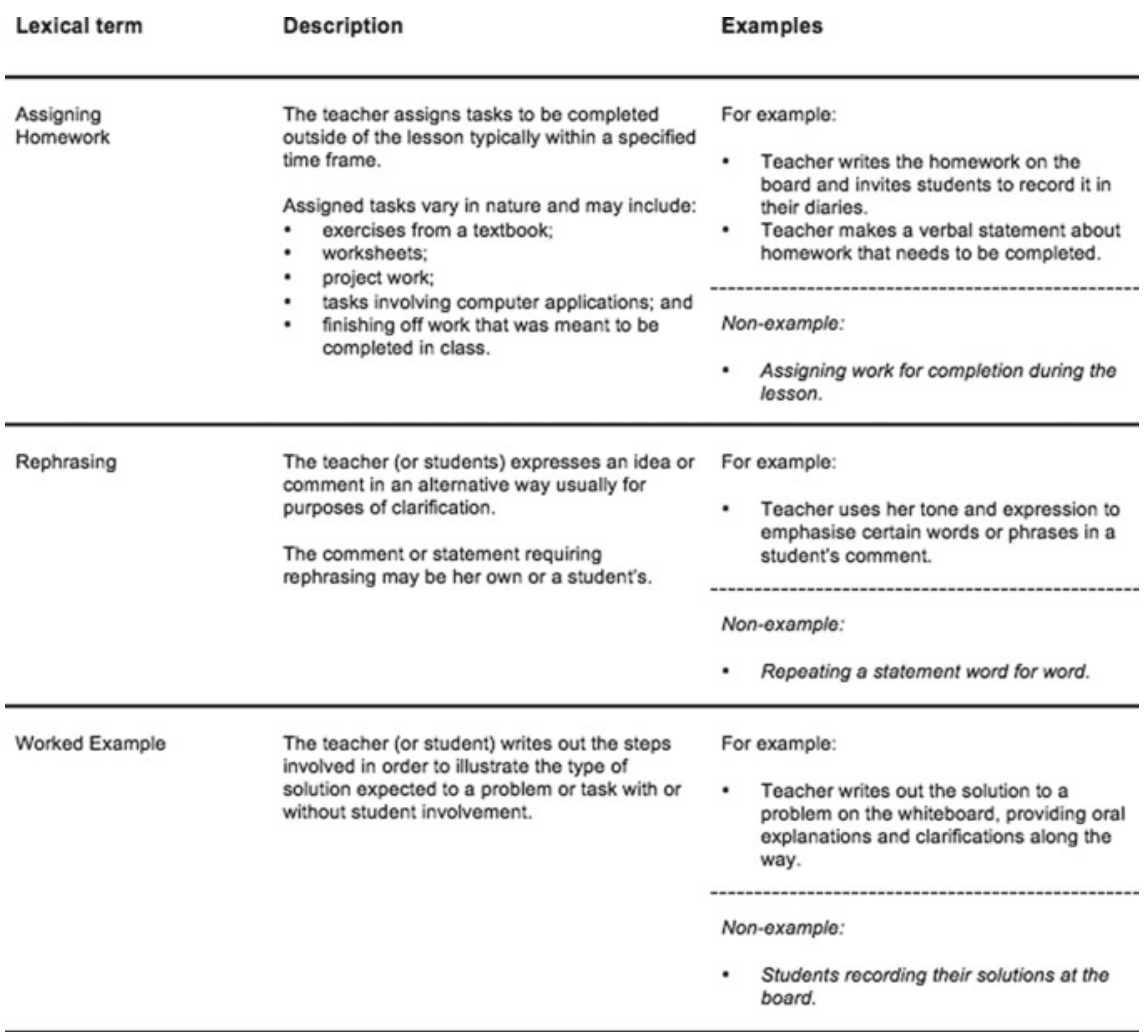

Fig. 9.8 A sample of operational definitions developed for terms in the Australian lexicon

process, Clarke and Chan noted that video can be employed as a research tool within a variety of research paradigms. The choice of words that researchers use to describe and report on the research process and resultant accounts (e.g., see, focus, reflect, and represent) can be an indication of the implicit or explicit assumptions of the researchers about their relationship with the data and with the phenomenon of interest. Clarke and Chan identified these perspectives with the metaphors: window, lens and mirror: Window describes the way videos are used in a study to assist researchers to look inside the classroom (see); lens describes the way videos are used by researchers to focus on selected aspects of classroom activity (focus); and mirror describes the way videos are used to catalyse teacher and student reflection on their own practice (reflect). A further metaphor, distorting mirror, describes the way in which video provides a rich data source for data re-construction and re-constitution based on researchers' own values and perspectives (represent). No single project is exclusively to be identified with a single metaphor. However, the metaphors appear to be useful for distinguishing between the different ways in which video material can be used in a research study. 
Clarke and Chan (2019) posit that consideration of these metaphors draws attention to some of the ontological and epistemological biases and assumptions implicit in educational research. The current chapter focuses particularly on the ontological grounding in terms of researcher role and the status of the video material, and represents the researchers' ontological options by the three metaphors (window, lens, and mirror). As will be discussed, the role of the researcher and the status of the video material in a study constitute a complex co-determining relationship. The three research projects, previously described, provide illustrative examples for the discussion.

\subsubsection{The Ontological Grounding of the Three Metaphors}

Each of the window, lens, and mirror metaphors corresponds to a particular ontological position in relation to the role that the video material fulfils within a study. For the window metaphor, the video material represents a reality that is assumed to exist external to the researcher. For the lens metaphor, the video material is a representation of the classroom constructed by the researcher through the orchestration of the research setting and conditions and data selection. The mirror metaphor characterises the way in which video material can be used by some researchers to catalyse reflective responses from participants as a source of data. In such studies, the video material does not serve the function of data, but rather serves as a research tool, similar to an interview protocol, test, or questionnaire, to elicit data from respondents. The use of video for such purposes in a study does not necessarily imply any particular ontological assumption, but accords ontological authority to the accounts which it is the role of the video to stimulate. Depending on the intended use of the participants' reflective responses in the study, the responses can be treated as a co-constructed reality for the participants and the researcher or a reality separate from the researcher. Each of these metaphors and associated ontological assumptions suggest different relationships between the researcher and the video material, and differences in the role that the researcher and the video material each plays within a study.

\subsection{The Co-determining Nature of the Role of the Researcher and the Status of the Video Material}

Rather than assuming that the researcher has full control and freedom to determine the status of the video material within a research study, we argue that the nature of the role of the researcher and the status of the video material within a study is to a certain extent co-determined. The researcher frames through the study design the purpose for which the video material is to be used in the study, which in turn 
determines the possible roles that the researcher can play in the study. For example, if the researcher collects video data to test a certain hypothesis, where the video is used as evidence for or evidence against a specific hypothesis, the video material is framed in a way that gives it innate veracity, appealing to its own intrinsic truth and authority to affirm or contest a proposition. Such ontological positioning has methodological entailments. If the video is accorded 'factual' status, providing access to a reality that is external to the researcher, then the researcher is obliged to minimise his or her role in distorting that reality, possibly leading to methodological adjustments.

On the other hand, if the researcher assumes the role of a 'film director' or a 'portrait photographer' and plays an active role in constructing the conditions in which the phenomenon of interest is to be recorded, then the resulting video is seen not as a window into reality but as an artefact of the research; representing a filtered and partial version of reality. The observation "all photographs are accurate; none of them is the truth", according to renowned portrait photographer Richard Avedon (Brown 2002), captures the paradoxical nature of video as research evidence. In such situations, where the researcher exercises significant control over the research setting and the manner in which it is recorded, the researcher is obliged to justify explicitly his or her decisions in constructing the research conditions and to present a theoretically coherent rationale. The status of the video material and the role of the researcher are therefore intertwined, since the form and function accorded to the video material within any research project will reflect the extent to which the researcher orchestrated both what was recorded on video and the type of analysis to which this video material was subjected.

\subsection{The Role of the Researcher and the Status of the Video Material in the Three Projects}

The three research projects (i.e., the LPS, the Social Unit of Learning project, and the Lexicon Project) can be contrasted in terms of the ontological grounding of their research designs and the role that the researcher and the video material each plays within the study.

In the LPS, the aim of the project was to document classroom practice in different classrooms in multiple countries. The LPS project design appealed to a naturalistic research paradigm, analogous to ethnographic approaches, in which the goal is the detailed documentation of community practices and normative activities undisturbed by the presence of the researcher. Video served as a window for researchers to see into the classrooms participating in the project (Clarke and Chan 2019). The research team acted as observers looking into these classrooms, and the video material gave access to a form of 'classroom reality' external to the research team. The classroom videos were seen as providing a factual record of that classroom reality. The many research reports (including five books), generated by LPS 
team members from all participating countries, addressed the challenge of describing the practices of those classrooms studied around the world and of identifying both distinctive features of each classroom but also common event types that might serve as vehicles for comparison between classrooms. "Lesson events" such as "Beginning the Lesson," "Between Desks Instruction" (what the Japanese call "Kikan-Shido"), "Student at the Front" and "Matome" (the Japanese term for summative discussion) were described and analysed in detail by Clarke et al. (2006a). Extensive investigation of Kikan-Shido in the video records of 150 lessons in 15 eighth-grade mathematics classrooms located in Australia (Melbourne), China (Hong Kong and Shanghai), Japan (Tokyo), and the USA (San Diego) led to the documentation of individual teachers' deployment of Kikan-Shido and the identification of 15 distinct purposes for which teachers in the various countries carried out Kikan-Shido in their classrooms (O'Keefe et al. 2006).

The LPS research design sought to enhance the power of in-depth case studies through comparison of classrooms in a variety of cultural settings. In designing the study, the research team had to ensure the 'cleanliness' and 'clarity' of the window (video) by minimising the possible distorting impact of their intrusion on the activities of the participants. This was achieved by allowing the teacher and students a familiarisation period of at least two to three lessons in which to become accustomed to the presence of the researchers and the video equipment in the classroom. Filming for the purpose of data generation commenced only once the teacher confirmed that the activities of the classroom approximated normality. In terms of the window metaphor, this was interpreted as indicating that normal classroom practice could be seen through the window of the video with minimal distortion and optimal clarity.

In the case of the Social Unit of Learning project, the project design can be seen as more akin to design experiments (Cobb et al. 2003), which involve "both 'engineering' particular forms of learning and systematically studying those forms of learning within the context defined by the means of supporting them" (p. 9). The main research design feature of the project was the use of the SLRC for observing and recording student-student and teacher-student interactions. The agency of the researchers in implementing the research design and in determining the data generated was acknowledged explicitly by the researchers, who reported that the research use of the SLRC facility "necessitates decisions concerning what to constrain and what to emulate within the laboratory classroom setting" (Chan and Clarke 2019). For example, the researchers determined the problem solving tasks with which the students were to engage and the social units (individual, pair, or, small group) through which the tasks were to be completed by the students. The research team exploited the control afforded by the laboratory classroom to optimise student positioning in order to generate comprehensive high-resolution audio-visual recording of student collaborative activity. Like a film director, the research team had extensive control over the video camera angle and focus, as well as over the supplementary data to be collected (e.g., student written work and pre- and post-lesson teacher interviews). 
Given the extensive and detailed multimodal data generated from the laboratory classroom, the researchers had to be selective in their choice of data to be analysed, similarly to the way a camera lens works in terms of zooming in or out to adjust the focus of the analysis. The video material in the Social Unit of Learning project was accorded the status of a constructed artefact resulting from the conditions purposefully orchestrated by the researcher. Through prescribing the types of tasks being carried out by intact classes of students with their teacher and varying the social unit of the activities, the project intended to provide a greater understanding of the learning ecology (cf. Cobb et al. 2003, p. 9) of mathematics classrooms focusing on the social nature of the classroom setting. The project was designed specifically to serve the purpose of theory generation and testing through the application of a multitheoretic research design, taking advantage of the extensive data that can be generated by the laboratory classroom facility.

The principal purpose of the Lexicon Project (Mesiti and Clarke 2017b) was the construction of national lexicons representing the professional vocabulary familiar to and employed by each teacher in each country. Each such lexicon documented the actual terms by which teachers name the phenomena of the mathematics classroom. A striking feature of the Lexicon Project was the use of a stimulus package of video-recorded lessons as a key catalyst for data generation. The primary purpose of the video material was to stimulate thinking about candidate terms for the lexicon and it was these candidate terms (and not the video) that operated as data in the project. There was neither prescription nor restriction (either of content or of pedagogy) as to which lesson of middle school mathematics was recorded in each community and the researchers in each country were free to choose the school and the teacher for the recording. It was agreed, however, that capturing a variety of classroom situations and instructional approaches would facilitate the production of a diversity of candidate lexical terms. In other words, the resulting kaleidoscope of classroom situations, given the variety of international communities involved in the project, would benefit the research team in two ways:

1. The package of stimulus video material would be more extensive and therefore function more effectively as stimulus material; and

2. The initial production of lexical terms would be more likely to simulate respondent recollection or recognition of additional and related terms.

As the primary aim of the project was to record the professional vocabulary of the teaching community in each participating country, video illustrations of each term were useful, but did not serve as a condition to determine the inclusion of a term in a lexicon. Composite operational descriptions were developed for the resulting lexical items and these were subjected to a variety of local and national validation procedures. Researchers in each country sought to determine whether the lexicon was a reasonable reflection of the professional vocabulary of the community of teachers in that country.

A close parallel to the methodology employed in the Lexicon Project is what Kelly (1955) called the "projective approach" to clinical interview in which 
self-reflective statements were elicited from respondents using photographic images as stimulus. The role of the researcher in this case is to provide the stimulus to catalyse the interviewee's reflection and to sort and organise those reflections. The researcher can be seen as a biographer or historian who collects memories from people and organises them into a coherent narrative, constructing some aspects of the life of interviewees. However, unlike biographical or historical accounts, in the Lexicon Project, the lexicon was not structured purely by chronology, but was intended to reflect connections or associations made by the community from whose responses the lexicon was constructed.

In summary, the three research projects (i.e., the LPS, the Social Unit of Learning project, and the Lexicon Project) offer examples of different uses of video in research studies. The projects can be contrasted in terms of the ontological grounding of their research designs and the role that the researcher and the video material each plays within the study. Illustrative of the window metaphor, the classroom videos were accorded the status of factual record within the LPS, giving researchers access to a form of 'classroom reality'. The research team acted as observers looking into the classrooms through the video material to identify distinct cultural features of different classrooms. In the Social Unit of Learning project, the role that the research team played was analogous to that of a film director in the orchestration of the research condition and setting and in the data selection. As a constructed artefact, the video material served as a lens for the purpose of theory generation and testing. In the Lexicon Project, the video material was used as a probing tool for eliciting participant reflective responses. Pedagogical terms were elicited from the teaching community by consideration of the video material. It was the role of the project team to organise and structure these pedagogical terms in a way that reflected connections and meanings held by that community. As a total construction, the resulting lexicon was a structured array of locally meaningful terms that could be compared to the account of an individual's life and circumstances constructed by an experienced biographer.

The assigned role of the video in each of the three studies determined the relationship that the researchers have with the data, and the function and form of reality that the video represented.

\subsection{Implications}

In this chapter, we identify ontological contingencies relevant to video-based research studies through examining the relationship between researcher and video material and, by association, the role between researcher and data. Video has the seductive appeal of a surrogate reality and the video record should not be confused in a research design with the events and situations it was intended to reproduce. Explicating the role of the researcher and the status of the video material within a study and the ontological contingencies implicit in the research design can help researchers to make informed decisions in the research process, from research 
design and data analysis, through to reporting. An awareness of the ontological contingences relevant to video-based educational research (and any research study), allows practitioners, policymakers, and other stakeholders to read research reports in a critical way, with an understanding of the limits and the validity of the claims provided in such reports.

We have identified key issues that determine the ontological status of the video material. These issues concern the role played by the researcher as the agentic constructor of the video material, and the question of whether authority is accorded to the video material as being in some way representative of a reality that exists independently of the researcher. In projects where the researcher has actively manipulated the research setting and process of data generation, the resultant video material is less able to be treated as representative of an objective and independent reality being studied by the researcher. A complex social setting such as the classroom has idiosyncratic features that limit the generalisability of the phenomena found in any particular classroom to other classrooms. The appeal in the LPS project to the naturalistic research paradigm stands in contrast to the use of the experimental approach in the Social Unit of Learning project. In each case, the authority for extrapolating findings to other situations or other individuals is differently warranted, and it is our assertion that the warrant to extrapolate or generalise from the study of one classroom setting to another depends critically on both the role of the researcher and the status of the video material, which we have argued are co-determining. In the Lexicon Project, the video material did not have a status as data but was employed as a catalytic research tool intended to elicit useful responses from participant teachers. The research team elicits from different teaching communities detail about their perception of their world, their practices, their values, and their beliefs, and organise them into a coherent narrative to understand the connections and meanings held by different communities. These three projects each illustrates a different relationship that the research team has with the video data. It is our intention to inform the practices of video-based research in education through foregrounding these different possible ways in which video can be used in a study together with the associated ontological assumptions.

The three illustrative cases of how videos are being used in research projects offer prototypes of the relationship between researcher and video that some researchers may find relevant to their research goals. Recognition of the co-determining relationship between researcher and video, and awareness of the metaphors that may characterise the roles of the video material in a research study, make clear that variations in the researcher's role find their echo in differences in the status of the video material as data. This relationship of reciprocal dependence between the role of the researcher and the ontological status of the video material must be taken into account during the process of research design. In short, changing the status of the video material in a research study (e.g., between documented reality and constructed representation) changes the role that the researcher plays, and vice versa.

We argue that researchers, when designing a research study employing video, need to make conscious decisions regarding the role that they themselves play and 
that of the associated video material. Each such decision needs to attend to considerations such as the research question(s), the phenomenon of interest, and the intended generalisability of the findings. This chapter illustrates the different roles that video material can play within a study. Before deciding to employ video as a research tool in classroom research, researchers can ask the following question: Are we going to treat what is captured in the video as a representation of classroom reality, a representation of a contrived classroom situation, or a form of stimulus intended to elicit further data?

The researcher's answer to this question will determine whether the researcher decides to exert influence on the research setting, which will in turn affect how the research findings can be reported. Careful ontological examination is needed before claims and recommendations can be made about particular classroom practices. Such ontological examination places limits on the generalisability of findings drawn from video data.

We also hope that readers of research (whether researchers, practitioners, policy makers, or other stakeholders) will be led to ask themselves which metaphor is being employed in the study reported or being read, and what are the implications for the readers' interpretation of the study findings and their application of those findings to settings of significance to them. As raised by Clarke and Chan (2019), it is not our intention to privilege one metaphorical alternative over another. Each metaphor has its domain of applicability consistent with the research design for which it has been recruited. There is a need to acknowledge such recruitment as the consequence of a choice by the researcher. The complicity of readers in interpreting research reports also must be acknowledged. Through this chapter, we hope to make different ontological contingencies visible in order to inform the practice, reporting, and interpretation of video-based research in education.

\section{References}

Amidon, E. J., \& Hough, J. B. (1967). Interaction analysis: Theory, research, and application. Reading, MA: Addison-Wesley Publishing Company.

Beeby, T., Burkhardt, H., \& Fraser, R. (1979). Systematic classroom analysis notation. Nottingham, England: Shell Centre for Mathematics Education.

Bourke, S. F. (1984). The teaching and learning of mathematics: National report of the second phase of the IEA Classroom Environment Study. ACER research monograph no. 25. Hawthorn, Victoria: Australian Council for Educational Research.

Brown, J. (2002). An Avedon portrait. The NewsHour with Jim Lehrer [Television news coverage]. United States: Public Broadcasting Service.

Chan, M. C. E., \& Clarke, D. J. (2017a). Learning research in a laboratory classroom: Complementarity and commensurability in juxtaposing multiple interpretive accounts. In T. Dooley \& G. Gueudet (Eds.), Proceedings of the Congress of European Research in Mathematics Education, Dublin, Ireland (pp. 2713-2720).

Chan, M. C. E., \& Clarke, D. J. (2017b). Structured affordances in the use of open-ended tasks to facilitate collaborative problem solving. ZDM-The International Journal on Mathematics Education, 49, 951-963. https://doi.org/10.1007/s11858-017-0876-2. 
Chan, M. C. E., \& Clarke, D. J. (2019). Video-based research in a laboratory classroom. In L. Xu, G. Aranda, W. Widjaja \& D. Clarke (Eds.), Video-based research in education: Cross-disciplinary perspectives (pp. 107-123). New York: Routledge.

Chan, M. C. E., Clarke, D. J., \& Cao, Y. (2017). The social essentials of learning: An experimental investigation of collaborative problem solving and knowledge construction in mathematics classrooms in Australia and China. Mathematics Education Research Journal, 30(1), 39-50. https://doi.org/10.1007/s13394-017-0209-3.

Chan, M. C. E., Ochoa, X., \& Clarke, D. J. (in press). Multimodal learning analytics in a laboratory classroom. In M. Virvou, E. Alepis, G. A. Tsihrintzis, \& L. C. Jain (Eds.), Advances in learning analytics. Cham, Switzerland: Springer.

Clarke, D. J. (Ed.). (2001). Perspectives on practice and meaning in mathematics and science classrooms. Dordrecht, The Netherlands: Kluwer Academic Publishers.

Clarke, D. J. (2006). The LPS research design. In D. J. Clarke, C. Keitel, \& Y. Shimizu (Eds.), Mathematics classrooms in twelve countries: The insider's perspective ( $\mathrm{pp}$. 15-36). Rotterdam, The Netherlands: Sense Publishers.

Clarke, D. J., \& Chan, M. C. E. (2019). The use of video in classroom research: Window, lens or mirror. In L. Xu, G. Aranda, W. Widjaja \& D. Clarke (Eds.), Video-based research in education: Cross-disciplinary perspectives (pp. 5-18). New York: Routledge.

Clarke, D. J., Emanuelsson, J., Jablonka, E., \& Mok, I. A. C. (Eds.). (2006a). Making connections: Comparing mathematics classrooms around the world. Rotterdam, The Netherlands: Sense Publishers.

Clarke, D. J., Keitel, C., \& Shimizu, Y. (Eds.). (2006b). Mathematics classrooms in twelve countries: The insider's perspective. Rotterdam, The Netherlands: Sense Publishers.

Clarke, D. J., Mesiti, C., Jablonka, E., \& Shimizu, Y. (2006c). Addressing the challenge of legitimate international comparisons: Lesson structure in the USA, Germany and Japan. In D.

J. Clarke, J. Emanuelsson, E. Jablonka, \& I. A. C. Mok (Eds.), Making connections: Comparing mathematics classrooms around the world (pp. 23-45). Rotterdam, The Netherlands: Sense Publishers.

Clarke, D. J., Xu, L. H., Arnold, J., Seah, L. H., Hart, C., Tytler, R., \& Prain, V. (2012). Multi-theoretic approaches to understanding the science classroom. In C. Bruguière, A. Tiberghien, \& P. Clément (Eds.), E-Book Proceedings of the ESERA 2011 Biennial Conference: Part 3 (pp. 26-40). Lyon, France: European Science Education Research Association.

Cobb, P., \& Bauersfeld, H. (1995). The emergence of mathematical meaning: Interaction in classroom cultures. Hillsdale, NJ: L. Erlbaum Associates.

Cobb, P., Confrey, J., diSessa, A., Lehrer, R., \& Schauble, L. (2003). Design experiments in educational research. Educational Researcher, 32(1), 9-13.

Díez-Palomar, J. (2017). Analyzing dialogic talk during mathematics problem solving in small groups. In B. Kaur, W. K. Ho, T. L. Toh, \& B. H. Choy (Eds.), Proceedings of the 41 st Annual Meeting of the International Group for the Psychology of Mathematics Education (Vol. 2, pp. 281-288). Singapore: PME.

Erlwanger, S. H. (1975). Case studies of children's conceptions of mathematics. Journal of Children's Mathematical Behaviour, 1(3), 157-283.

Givvin, K. B., Hiebert, J., Jacobs, J. K., Hollingsworth, H., \& Gallimore, R. (2005). Are there national patterns of teaching? Evidence from the TIMSS 1999 video study. Comparative Education Review, 49, 311-343.

Good, T. L., \& Grouws, D. A. (1977). Teaching effects: A process-product study in fourth-grade mathematics classrooms. Journal of Teacher Education, 28(3), 49-54. https://doi.org/10.1177/ 002248717702800310.

Hiebert, J., Gallimore, R., Garnier, H., Givvin, K. B., Hollingsworth, H., Jacobs, J., et al. (2003). Teaching mathematics in seven countries: Results from the TIMSS 1999 video study (NCES 2003-013 Revised). Washington, DC: U.S. Department of Education, National Center for Education Statistics. Retrieved from http://nces.ed.gov/pubsearch/pubsinfo.asp?pubid= 2003013. 
Kelly, G. (1955). The psychology of personal constructs. New York: Norton.

Mesiti, C., \& Clarke, D. (2017a). The international lexicon project: Giving a name to what we do. In R. Seah, M. Horne, J. Ocean, \& C. Orellana (Eds.), Proceedings of the Mathematical Association of Victoria annual conference, Brunswick, Australia (pp. 31-38).

Mesiti, C., \& Clarke, D. (2017b). Structure in the professional vocabulary of middle school mathematics teachers in Australia. In A. Downton, S. Livy, \& J. Hall (Eds.), Proceedings of the conference of the Mathematics Education Research Group of Australasia, Melbourne, Victoria, Australia (pp. 373-380).

Neuman, W. L. (2014). Social research methods: Qualitative and quantitative approaches (7th ed.). Essex, England: Pearson Education Limited.

O'Keefe, C., Xu, L. H., \& Clarke, D. J. (2006). Kikan-Shido: Between desks instruction. In D. J. Clarke, J. Emanuelsson, E. Jablonka, \& I. A. C. Mok (Eds.), Making connections: Comparing mathematics classrooms around the world (pp. 73-106). Rotterdam, The Netherlands: Sense Publishers.

Prediger, S., Bikner-Ahsbahs, A., \& Arzarello, F. (2008). Networking strategies and methods for connecting theoretical approaches: First steps towards a conceptual framework. ZDM-The International Journal on Mathematics Education, 40(2), 165-178. https://doi.org/10.1007/ s11858-008-0086-z.

Schirmer, B. R., Lockman, A. S., \& Schirmer, T. N. (2016). Identifying evidence-based educational practices: Which research designs provide findings that can influence social change? Journal of Educational Research and Practice, 6(1), 33-42.

Simpson, A. (2017). The misdirection of public policy: Comparing and combining standardised effect sizes. Journal of Education Policy, 32(4), 450-466. https://doi.org/10.1080/02680939. 2017.1280183.

Stigler, J. W., \& Hiebert, J. (1999). The teaching gap: Best ideas from the world's teachers for improving education in the classroom. New York: Free Press.

Tran, D., \& Chan, M. C. E. (2017). Examining mathematical sophistications in collaborative problem solving. In B. Kaur, W. K. Ho, T. L. Toh, \& B. H. Choy (Eds.), Proceedings of the 41st Annual Meeting of the International Group for the Psychology of Mathematics Education (Vol. 4, pp. 281-288). Singapore: PME.

Tuohilampi, L. (2018). Analyzing engagement in mathematical collaboration: What can we say with confidence? In E. Bergqvist, M. Österholm, C. Granberg, \& L. Sumpter (Eds.), Proceedings of the 42nd Annual Meeting of the International Group for the Psychology of Mathematics Education (Vol. 1, pp. 235-242). Umeå, Sweden: PME.

Open Access This chapter is licensed under the terms of the Creative Commons Attribution 4.0 International License (http://creativecommons.org/licenses/by/4.0/), which permits use, sharing, adaptation, distribution and reproduction in any medium or format, as long as you give appropriate credit to the original author(s) and the source, provide a link to the Creative Commons license and indicate if changes were made.

The images or other third party material in this chapter are included in the chapter's Creative Commons license, unless indicated otherwise in a credit line to the material. If material is not included in the chapter's Creative Commons license and your intended use is not permitted by statutory regulation or exceeds the permitted use, you will need to obtain permission directly from the copyright holder. 